\title{
THERMO-MECHANICAL MODELLING FOR THE OPENING OF ELECTRON-BEAM WELDED JOINTS
}

\author{
Muriel CARIN \\ Philippe ROGEON \\ Laboratoire d'Etudes Thermiques, \\ Energétiques et Environnement \\ (LET2E) \\ Université de Bretagne-Sud \\ Centre de Recherche \\ Rue de Saint-Maudé \\ 56321 LORIENT Cedex, France \\ muriel.carin@univ-ubs.fr
}

\author{
Pierre-Yves MANACH \\ Philippe PILVIN \\ Laboratoire Génie Mécanique et \\ Matériaux (LG2M) \\ Université de Bretagne-Sud \\ Centre de Recherche \\ Rue de Saint-Maudé \\ 56321 LORIENT Cedex, France
}

\author{
Olivier MENES \\ Jean-François SIGRIST \\ Service Technique et Scientifique \\ DCN Propulsion \\ 44620 LA MONTAGNE, France
}

\begin{abstract}
The aim of this study is to estimate residual stresses and distortions during the assembly of dissimilar metallic materials welded by Electron Beam Welding (EBW) technique. This work is motivated by a new welding procedure for the manufacture of large speed reduction gear. The gear consists of a central hub of S275J2G3 steel and a toothed wheel of $32 \mathrm{CrMoV} 13$ steel, chosen for its high fatigue performances. Preliminary experimental welding tests have shown the opening of the joint plane during the circular welding of the gear leading to lack-of-fusion defects.

To improve the joining technique, a thermomechanical model has been developed to predict the opening of the joint plane during welding. A two-dimensional finite element model has been applied on a simplified geometry of smaller size. The opening of the joint plane has been modelled by two different ways, the first one uses activation / deactivation elements and the second one uses specific contact elements. Both techniques have shown similar displacements. The assumptions of plane stress or generalized plane strain are discussed. Numerical results obtained with similar metals with or without metallurgical transformations are presented. Calculations carried out with dissimilar metals are compared with experiments in terms of fusion zone size and displacements.
\end{abstract}

\section{INTRODUCTION}

Electron-beam welding (EBW) remains an important manufacturing process, particularly in the automobile, aerospace, construction and power-generation industries. Such high power density welding processes produce welds with high aspect ratio and narrow heat-affected zone with low heat distortions. Electron-beam welding also offers the attractive feature to join dissimilar metals, which may be difficult or impossible to weld by other conventional welding processes.
However, the severe thermal cycles in a welding process induce stresses and distortions during welding leading to residual stresses and distortions. These take place primarily due to different rates of expansion and contraction which occur as the various metals solidify in the welding zone and cool to ambient. This usually cause brittle fracture, cracking, affecting therefore the structural performance.

Furthermore the deformations occurring during welding can lead to the opening of the weld joint if no care is taken. In general, tack welds are made to hold the minimum gap required for a successful weld. However, improperly made tack welds may create problems that result in the propagation of cracks [1].

The background for this work is the assembly of a central hub with a toothed wheel in the design of a speed reduction gear. The choice of the geometry involves a full penetration weld in the presence of dissimilar materials. Preliminary experimental welding tests have shown the opening of the joint plane during the circular welding of the gear leading to lack-of-fusion defects. The opening of the weld joint during welding is due to thermal, metallurgical and mechanical coupled phenomena. Numerical simulation can be useful to predict the distortion gap width resulting from the welding process. Finite element method is widely applied to the analysis and simulation of welding processes (see [2,3] for a review). The distortion gap width that arises ahead of a butt weld in laser welding was previously investigated both analytically and numerically by Dain [4]. This work was restricted to the plane linear thermoelastic model applied to infinite half planes. It was shown that the welding procedure has a large influence on the 
change in gap width, which was in good agreement with the results published by Lindgren [5].

In this work, a thermomechanical-metallurgical model has been developed to predict the opening of the joint plane during welding. The finite element model has been applied on a simplified geometry of smaller size than the gear and compared to experimental data. Nevertheless, the thickness and materials used for this simplified case are identical to the real case.

\section{EXPERIMENTAL SET-UP}

The simple welding assembly comprises upper and lower samples $35 \mathrm{~mm}$ thick separated by a sheet of Inconel 625 of 1 $\mathrm{mm}$ thickness. The presence of Inconel 625 prevents cracking in the weld joint and reduces the thermoelectric-magnetic deflection of the beam, particularly important in welding dissimilar metals [6]. Both specimen were cut from rectangular blocks with an inclined angle as shown in Figure 1 in order to vary the clamping conditions. The upper specimen is made of 32CrMoV13 steel, the lower is in S275J2G3 steel. As the thickness of the specimen is the same that the materials used for the gear $(35 \mathrm{~mm})$, the welding parameters are identical to those used for the gear : accelerating voltage $U=50$ $\mathrm{kV}$, current $\mathrm{I}=315 \mathrm{~mA}$, weld speed $\mathrm{V}=4.16 \mathrm{~mm} \cdot \mathrm{s}^{-1}$, focus current $\mathrm{If}=2.43 \mathrm{~A}$, working distance $\mathrm{dt}=160 \mathrm{~mm}$, beam oscillation frequency $=200 \mathrm{~Hz}$ and amplitude $=2.2 \mathrm{~mm}$, welding chamber pressure $=5.10^{-4}$ mbar. These parameters were optimised to ensure complete penetration joints in a single pass.

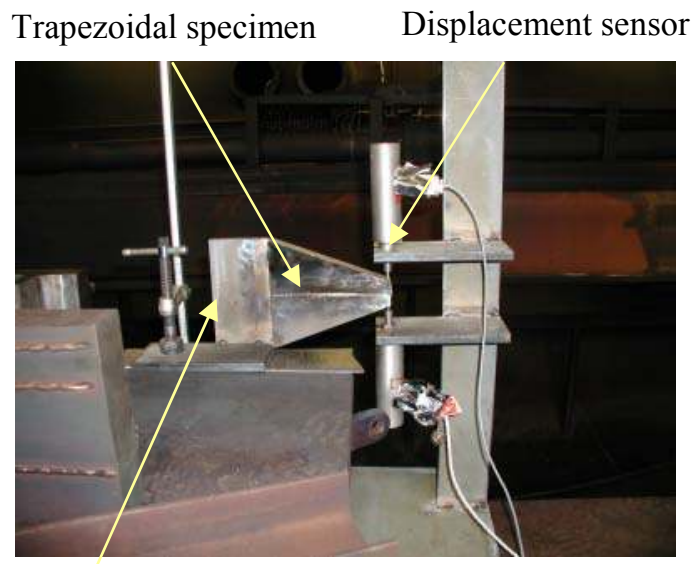

Clamping intermediate block

Figure 1: Experimental set-up.

The specimens were tack-welded to another plate of S275J2G3 steel in order to ensure the clamping conditions on one edge. The butt-welding started at $3.5 \mathrm{~mm}$ from this edge and the beam moved along the horizontal $\mathrm{x}$-axis with a constant velocity toward the opposite edge equipped with displacement transducers. The exterior edges of the trapezoidal plates are free. The assembly is placed vertically in the vacuum chamber and welded in a horizontal position by EBW at the DCN Indret ${ }^{1}$.

\section{FINITE ELEMENT MODELLING OF THE WELDING PROCESS}

\subsection{Thermo-mechanical model}

The problem consists of two trapezoidal plates in contact, clamped at one end and kept free on the other one, initially at $300 \mathrm{~K}$ submitted to a moving volumic heat source (Figure 3).

Two-dimensional simulations are performed to determine the opening of the joint plane during welding. For such problem, couplings between thermal, metallurgical and mechanical fields have to be considered. Metallurgical transformations depend on the thermal history and affect the thermophysical and mechanical properties. The latent heats of transformation are included in the heat transport equation. The mechanical equilibrium equation accounts for the effect of the thermal strain related to the phase and temperature dependent thermal expansion coefficients.

The rate of heat generation due to mechanical dissipation energy is usually neglected in the heat transfer analysis. Therefore the thermal analysis may be performed separately from the mechanical analysis. Firstly a non-linear transient thermometallurgical analysis is conducted. The metallurgical and thermal calculations are coupled and performed simultaneously. Subsequently, quasi static mechanical finite element analysis follows the thermometallurgical analysis and uses the computed temperature and phase histories as loading to calculate deformations and stresses.

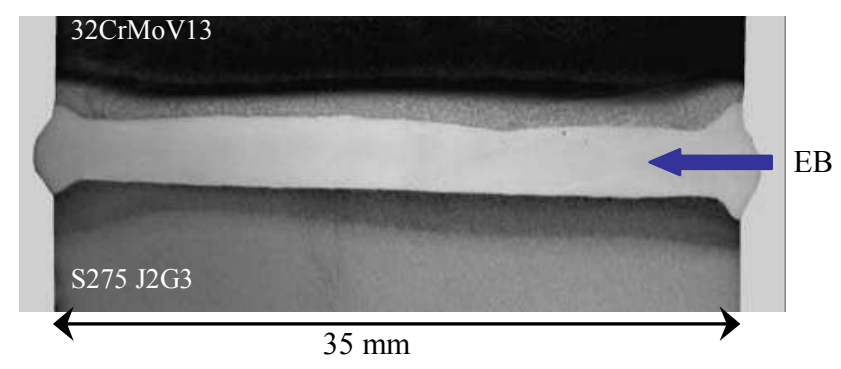

Figure 2: Transverse macrography of the welded joint.

In the present study, the calculations can be conducted in the longitudinal plane, thermal gradients are negligible in the thickness since the weld joint is relatively straight in the thickness (Figure 2) and strains take place mainly in the longitudinal plane due to the large thickness of the plates. The heat source input is modeled by a Gaussian volumic heat source moving along the workpiece at the electron-beam

\footnotetext{
${ }^{1}$ DCN Indret La Montagne 44000 Nantes, France
} 
velocity. The beam oscillation is not taken into account due to its weak effect on the temperature field [7]. Due to its small thickness, the Inconel 625 is completely melted in the fusion zone. Therefore to model accurately the fusion zone, it would require to access the properties of the alloy S275J2G3 / Inconel $625 / 32 \mathrm{CrMoV} 13$, which are not available in the literature.

The materials are assumed to be thermo-elastoplastic with isotropic hardening and temperature-dependent material properties. Volume changes due to phase transformations are accounted for in the thermal dilatation. Creep strains are not included in the mechanical analysis of welding, since the time spent at high temperatures is very short. Transformation plasticity is not taken into account in the present study.

Due to lack of available material data at elevated temperatures corresponding to the studied materials, data from material of similar composition were used. The material properties of the S275J2G3 steel are supposed close to the S355MC (HE360D) steel [8], whereas the properties of the $32 \mathrm{CrMoV} 13$ steel are taken close to the 16MND5 steel (French AFNOR norm) [9, 10]. The chemical compositions of the materials used in the experimental study are given in tables 1 to 3 .

\begin{tabular}{|l|l|l|l|l|l|l|l|l|l|}
\hline & $\mathrm{C}$ & $\mathrm{Cr}$ & $\mathrm{Mo}$ & $\mathrm{V}$ & $\mathrm{Si}$ & $\mathrm{Mn}$ & $\mathrm{S}$ & $\mathrm{P}$ & $\mathrm{Ni}$ \\
\hline wt.\% & 0.344 & 2.95 & 0.83 & 0.27 & 0.31 & 0.44 & 0.003 & 0.009 & 0.06 \\
\hline
\end{tabular}

Table 1: Chemical composition of $32 \mathrm{CrMoV} 13$ steel

\begin{tabular}{|l|l|l|l|l|}
\hline & C & Mn & S & N \\
\hline wt.\% & 0.18 & 1.5 & 0.035 & 0.035 \\
\hline
\end{tabular}

Table 2: Chemical composition of S275J2G3 steel

\begin{tabular}{|l|l|l|l|l|l|l|l|l|l|l|l|l|}
\hline & $\mathrm{C}$ & $\mathrm{Cr}$ & $\mathrm{Fe}$ & $\mathrm{Mo}$ & $\mathrm{Si}$ & $\mathrm{Mn}$ & $\mathrm{S}$ & $\mathrm{P}$ & $\mathrm{Co}$ & $\mathrm{Ti}$ & $\begin{array}{l}\mathrm{Nb} \\
\mathrm{Ta}\end{array}$ & $\mathrm{Al}$ \\
\hline $\begin{array}{l}\mathrm{wt} \\
. \%\end{array}$ & 0.1 & $\begin{array}{l}20.0- \\
23.0\end{array}$ & 5.0 & $\begin{array}{l}8.0- \\
10.0\end{array}$ & 0.5 & 0.5 & 0.015 & 0.015 & 1.0 & 0.4 & $\begin{array}{l}3.15- \\
4.15\end{array}$ & 0.4 \\
\hline
\end{tabular}

Table 3: Chemical composition of Inconel 625

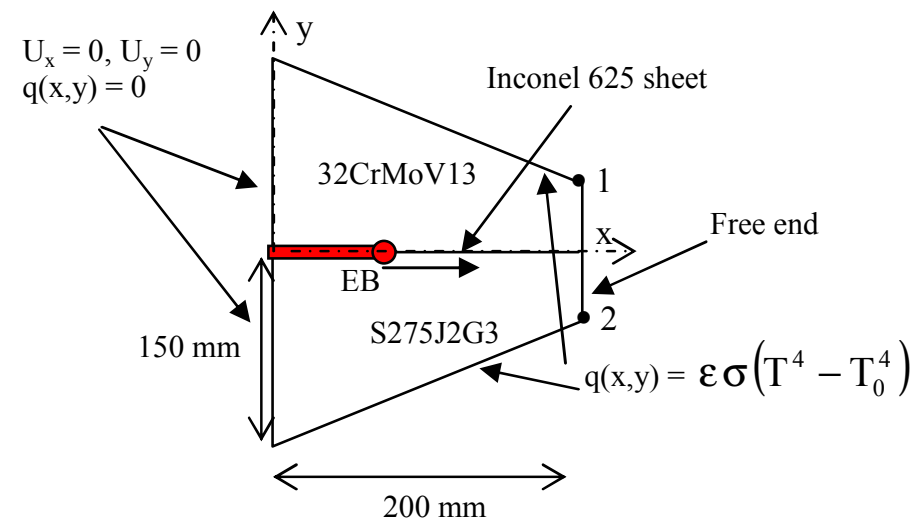

Figure 3: Schematic representation of the EBW process: trapezoidal plate with one clamped edge $\left(u_{x}=u_{y}=0\right)$ and the others free to move. The points 1 and 2 indicate the location of the displacement sensors.

\section{Thermal analysis}

The governing equation for the heat transfer is defined as follows using the enthalpy formulation:

$$
\rho \frac{\mathrm{dH}}{\mathrm{dt}}=-\nabla \cdot \overrightarrow{\mathrm{q}}+\mathrm{q}_{\mathrm{v}}(\mathrm{x}, \mathrm{y})
$$

where $\rho, H, q_{v}(x, y)$ are the density, the enthalpy and the volumic heat source term respectively.

The conductive heat flux $\overrightarrow{\mathrm{q}}$ is calculated from the Fourier law and is written for an isotropic material as:

$$
\overrightarrow{\mathrm{q}}=-\lambda \nabla \mathrm{T}
$$

in which $\lambda$ represents the thermal conductivity.

The thermal characteristics are determined using a linear mixture law of the amount of each phase present.

The heat source distribution produced by the electron-beam is assumed to be a normal Gaussian distribution and is defined by

$$
\mathrm{q}_{\mathrm{v}}(\mathrm{x}, \mathrm{y})=\frac{\eta \mathrm{UI}}{2 \pi \omega_{0}^{2} \mathrm{H}} \exp \left(-\frac{\left(\mathrm{x}-\mathrm{x}_{\mathrm{s}}(\mathrm{t})\right)^{2}+\left(\mathrm{y}-\mathrm{y}_{\mathrm{s}}(\mathrm{t})\right)^{2}}{2 \omega_{0}^{2}}\right)
$$

where $\eta$ is the efficiency of the energy transmission via electron-beam, $U$ is voltage, $\mathrm{I}$ is current intensity, $\mathrm{H}$ is the thickness of the workpiece, $\omega_{0}$ is the deviation from the standard distribution, $\mathrm{x}_{\mathrm{s}}(\mathrm{t}), \mathrm{y}_{\mathrm{s}}(\mathrm{t})$ are the coordinates of the centre of the beam at a given time $t$. For a source moving at a velocity $\mathrm{v}$ along $\mathrm{x}$-axis, $\mathrm{y}_{\mathrm{s}}(\mathrm{t})=0$ and $\mathrm{x}_{\mathrm{s}}(\mathrm{t})$ is given by:

$$
\mathrm{x}_{\mathrm{s}}(\mathrm{t})=\mathrm{v} \cdot\left(\mathrm{t}+\mathrm{t}_{0}\right)
$$

where $t_{0}$ is the time-delay to account for the initial position of the beam.

\section{Metallurgical transformations}

In this work, the metallurgical models employed are LeblondDevaux [11] for the diffusional transformations and Koistinen-Marburger for martensitic transformation [12]. The transformations are the austenitic transformation during heating and ferritic or martensitic transformation during cooling.

For the S275J2G3 steel, only ferritic and austenitic transformations are considered, since the cooling rate values are too small in our case to lead to martensitic transformation. Based on Vickers macrohardness measurements (around 350 HV10 in the base metal and 510 HV10 in the HAZ of the $32 \mathrm{CrMoV} 13$ steel), the following transformations for the $32 \mathrm{CrMoV} 13$ steel are considered :

- during heating : tempered martensite $\rightarrow$ austenite

- during cooling : austenite $\rightarrow$ quenched martensite 
If creep and transformations plasticity are not taken into account, the rate form of the strains can be written by assuming additive decomposition of the strains:

$$
\dot{\varepsilon}_{\text {tot }}=\dot{\varepsilon}_{\text {ela }}+\dot{\varepsilon}_{\mathrm{p}}+\dot{\varepsilon}_{\text {th }}
$$

where $\dot{\varepsilon}_{\text {tot }}, \dot{\varepsilon}_{\text {ela }}, \dot{\varepsilon}_{\mathrm{p}}, \dot{\varepsilon}_{\text {th }}$ are the total, elastic, plastic and thermal strain rate tensors, respectively.

Above the melting temperature, the history of prior straining is eliminated (annealing temperature) as the material transforms from solid to liquid state.

The mechanical computation also accounts for geometric nonlinearities; for instance, a large displacement formulation is used in order to correctly evaluate distortions.

\subsection{Computational model}

The numerical simulations were carried out both with SYSWELD [13] and ABAQUS [14]: two commercial finite element codes capable of weld simulations. The computational methodology used to simulate the opening of the joint plane is validated by comparing the computed results obtained from both codes.

The opening of the joint plane is modelled by two different ways. The first one uses the activation or deactivation of elements implemented in Sysweld and classically used to model a welding process with material deposit. The second one involves the use of specific contact elements between the two different steels and was employed in the Abaqus simulations.

In the element activation technique used only during mechanical analysis, all elements representing Inconel 625 ahead of the electron beam are deactivated by assigning them very low properties : deactivated elements are reactivated sequentially when they come under the influence of the heat source. The mechanical properties and phase transformations of these elements are supposed identical to those of the S275J2G3 steel. During the thermal analysis, the Inconel 625 sheet is supposed to have the thermal properties of S275J2G3 steel.

The simulations using the commercial software Abaqus were performed using interface elements with a friction coefficient of 0.1 between the two materials. The calculations use a fully coupled finite element analysis to solve the thermalmechanical analysis in which the thermal analysis is performed on a deformed mesh. The metallurgy is ignored but latent heats of fusion and vaporization are accounted for.

The mesh consists of 9750 linear elements and 10664 nodes and exhibits the same refinement for both codes (Figure 7). This mesh allows to find the same results with those obtained by finer grids. The thermo-mechanical problem solution is obtained using an adaptive time stepping algorithm.

\section{RESULTS}

\subsection{Experimental results}

The displacement history of the free ends was recorded during welding (Figure 4). A maximum distortion gap width of 1.2 $\mathrm{mm}$ is observed when the electron beam center is located at 18 $\mathrm{cm}$ from the clamped side. The width of the Heat Affected Zone (HAZ) and Fusion Zone (FZ) observed in the middle plane perpendicular to the welding direction remains constant along the first $12 \mathrm{~cm}$ and decreases beyond due to the separation of the two weld pieces involving the decrease of the welding process efficiency.

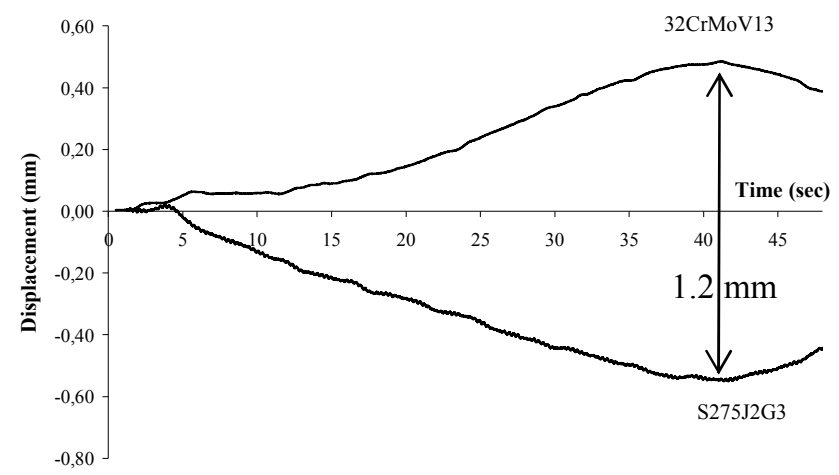

Figure 4: Time history of the sensors displacements.

\subsection{Computational results}

In order to validate the computation technique for the opening of the interface, simulations were conducted firstly with a unique material (S275J2G3 steel). Various assumptions are analyzed:

- technique used to model the opening of the joint plane,

- two-dimensional finite element modeling assumptions (plane stress or generalized plane strain),

- influence of the metallurgy.

The thermal field is validated by comparing calculated and measured width of heat affected zone and fusion zone $\left(\mathrm{L}_{\mathrm{HAZ}}=\right.$ $6.6 \mathrm{~mm}, \mathrm{~L}_{\mathrm{ZF}}=3.3 \mathrm{~mm}$ ). The efficiency was estimated to be 0.60 in order to have this good agreement. Furthermore, a good correlation between temperature profiles calculated by both commercial softwares is shown in Figure 5. The influence of metallurgical transformations on the temperature profiles was investigated using Sysweld (Figure 5). It is shown that temperatures calculated from the thermometallurgical model in the HAZ are slightly higher than the purely thermal model. This can be attributed to the lower thermal conductivity of the austenite phase. 


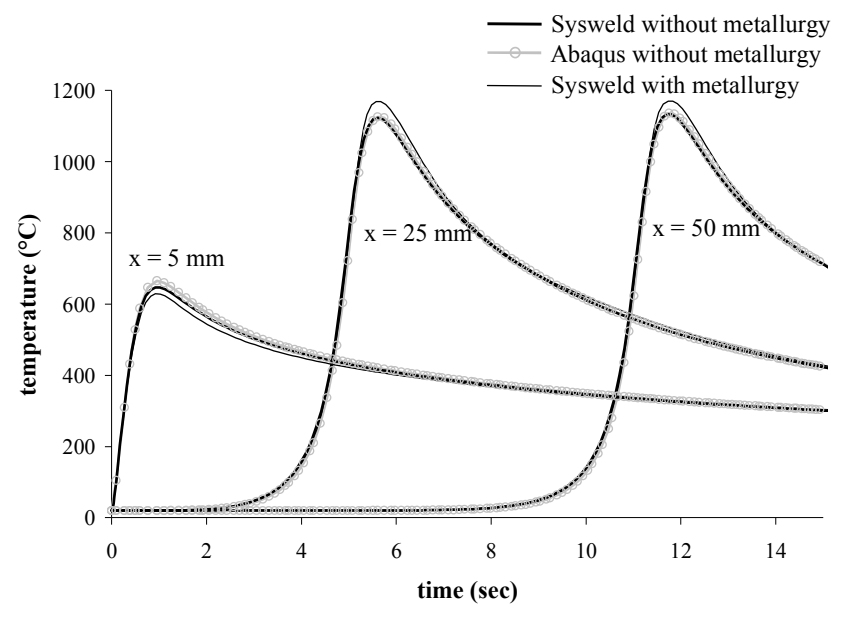

Figure 5: Temperature profiles at $y=2 \mathrm{~mm}$ from the weld line and various $x(x=5 \mathrm{~mm}, 25 \mathrm{~mm}$ and $50 \mathrm{~mm})$ calculated by Abaqus without metallurgy and Sysweld with or without metallurgy.

The calculated change in gap width is presented in Figure 6 for various assumptions. It can be noticed that the opening of the extremities appears immediately at the beginning of welding and varies quasi linearly with time.

The influence of two-dimensional finite element assumptions on the opening prediction is analyzed. Geometrically non linear finite element analyses using two-dimensional plane stress and generalized plane strain were performed. Generalized plane-strain conditions are assumed to account for the out-of-plane expansion in the structure. In that case, the structure is assumed to lie between two planes that can move with respect to each other. This causes strain along the normal direction to the plane of the model that varies linearly with respect to position in the planes. This assumption is generally adopted when the thickness is large compared to the area of the structure. A plane-stress model imposes the out of plane stresses to be zero $\left(\sigma_{\mathrm{zz}}=\tau_{\mathrm{xz}}=\tau_{\mathrm{yz}}=0\right)$. Hence plane stress condition is applied to describe the state of stresses in a flat, thin plate. In the case of the trapezoidal plates of $35 \mathrm{~mm}$ thick and around $20000 \mathrm{~mm}^{2}$ area, the plane stress assumption seems more adequate. This approach yields smaller distortion gap width compared to the generalized plane-strain model which exhibits a stiffer behavior.

No significant difference is observed on displacement between the case with or without metallurgy (figure 6). This could be attributed to two antagonist effects occurring in the HAZ when phase transformations are taken into account: during the heating stage, the increase of distortions due to higher temperatures and higher austenite thermal dilatation coefficient is probably balanced by metallurgical contraction as austenite appears.

Some discrepancies are observed between displacements calculated by both codes but do not exceed $10 \%$ although the technique used to model the opening is totally different in both cases. Using interface elements rather than activation elements lead to slightly larger displacements. Note that in the case of interface elements technique, a tangential displacement between the two welded parts is observed behind the weld pool. These results tend to validate the technique used to model the opening of the plane joint. Hence assimilate the interface by a thin and hyperelastic material ahead of the heat source can be equivalent to the use of specific contact elements and allows to describe the continuity of the matter behind the weld pool. Furthermore, this technique has the advantage to reduce computation time since the assembling matrix is then symmetric and allow the use of algorithm such as BFGS.

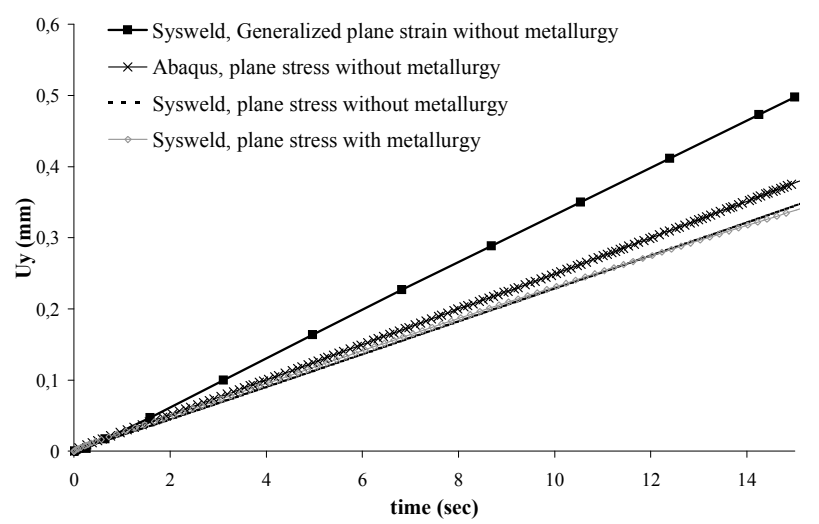

Figure 6: Comparison of the change in gap width calculated by the Abaqus or Sysweld code. Influence of the assumptions, twodimensional finite element (plane stress or generalized plane strain) and metallurgy.

An example of the deformed mesh obtained from Abaqus is shown in Figure 7.

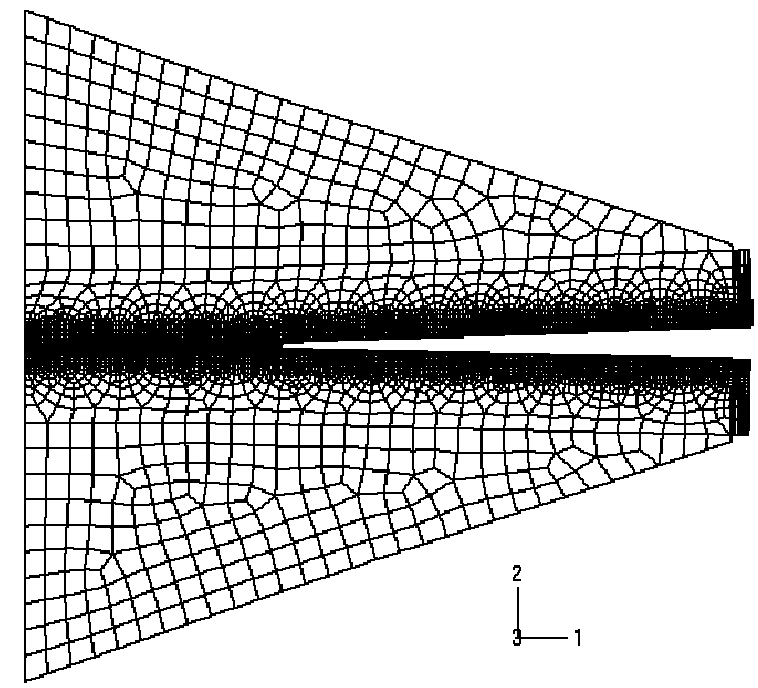

Figure 7: Example of deformed mesh obtained from Abaqus at $t=15$ $s($ deformation scale factor $=10)$ 
In the following results, the plane stress condition is retained. Calculations were performed considering dissimilar materials. A material similar to the $32 \mathrm{CrMoV} 13$ steel is chosen for the upper trapezoidal plate whereas a material close to the S275J2G3 steel is considered for the lower plate. The change in gap width is shown in Figure 8. The difference between displacements calculated by Sysweld and Abaqus are in close agreement and do not exceed $8 \%$ for both materials. The displacement $\mathrm{u}_{\mathrm{y}}$ of the free end is higher for the upper material than for the lower one. This is due to the higher yield strength of the upper material resulting in higher von Mises equivalent stresses as shown in Figure 9. The lower material thus exhibits earlier plastic deformations in the HAZ, which tend to reduce the displacement in the whole piece.

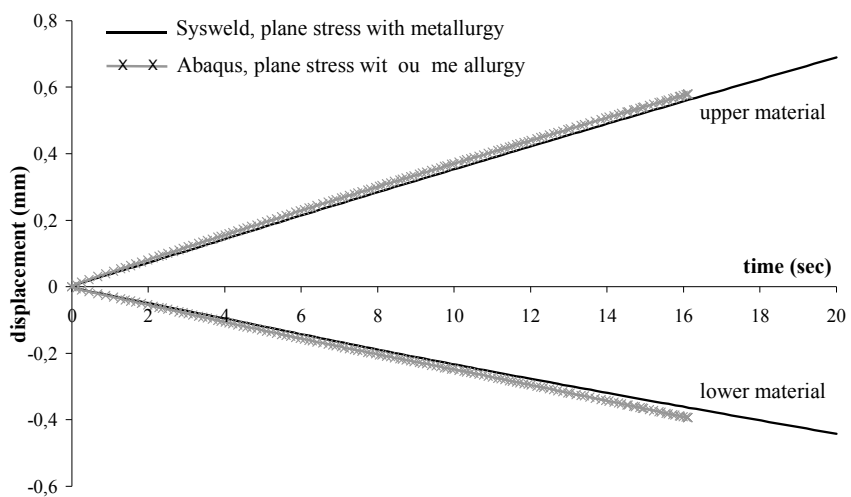

Figure 8: Comparison of the change in gap width calculated by the Abaqus or Sysweld code in the case of dissimilar materials.

The stress profile is almost identical in points located at $y= \pm$ $2 \mathrm{~mm}$ from the weld centerline and various $\mathrm{x}$ except at the point located at $x=5 \mathrm{~mm}$ due to the effect of the clamped condition. As the electron-beam approaches, the von-Mises equivalent stresses in the Heat Affected Zone increase. It is interesting to note that this increase appears at points where temperature is still low. As seen in Figure 8, the displacement of the free end occurs as soon as the heat source is applied, leading to a motion of rigid body clamped to one edge and undergoing a very local heating. This results in an increase of stresses particularly high in region close to the fusion zone. Ahead of the heat source, the stresses in the region beside the welding bead are initially tensile and turn to compressive as the heat source approaches. Therefore the point located at $\mathrm{x}=$ $25 \mathrm{~mm}$ initially moves aside from the welding centerline and then draws nearer as the fusion zone approaches. This explains the change in slope (point A) occurring before the maximum von-Mises stresses are reached (point B). Then stresses start to decrease due to plastic behavior of material immediately surrounding the welding bead. The stresses become zero at about $1160^{\circ} \mathrm{C}$ (point $\mathrm{C}$ ) for the point located at $\mathrm{x}=25 \mathrm{~mm}$ because of the decrease in yield strength at elevated temperatures and the effect of the nearby molten metal which does not support shear loading (modeled by the annealing temperature). During the subsequent cooling, the von-Mises equivalent stresses increase again due to the shrinkage of the material behind the welding bead. The influence of the phase transformations on the stresses is observed (point D) when temperature is around $700-800{ }^{\circ} \mathrm{C}$ during cooling corresponding to the austenite to ferrite transformation.

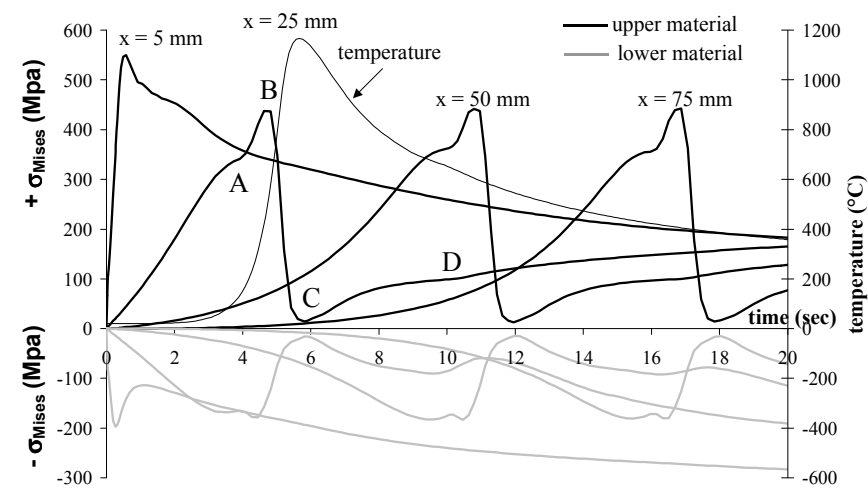

Figure 9: Time histories of von-Mises equivalent stresses at $y= \pm 2$ $\mathrm{mm}$ from the weld line and various $x(x=5,25,50$ and $75 \mathrm{~mm})$ for the welded trapezoidal plates calculated by Sysweld accounting for metallurgy in plane stress. For clarity of the figure, the von-Mises stresses of the lower material are represented along the negative $y$ axis. The time history of temperature is represented only at the point located at $x=25 \mathrm{~mm}$ in the upper material.

The numerical analysis was restricted to the first $20 \mathrm{~s}$ of welding, which correspond to the formation of a weld joint of around $8 \mathrm{~cm}$ long. Experimental observations have indicated that beyond the first $12 \mathrm{~cm}$ the weld joint shape decreases significantly. The gap between the two weld pieces is then filled with molten material due mainly to the fusion of the Inconel 625 steel sheet which remains on the electron beam path. A detailed modelling of this complex behavior is beyond the scope of this paper. Therefore, a limited analysis is conducted here to simulate only the first $20 \mathrm{~s}$ of the welding corresponding to a constant weld joint width. The agreement with the measured data seems to be poor, at first glance (Fig 4 and Fig 8). The calculated distortion gap is wider than the experimental values. For example, at $20 \mathrm{~s}$, the calculated displacement is around $1.1 \mathrm{~mm}$ whereas the displacement sensor indicates a value of only $0.44 \mathrm{~mm}$ However, the overall trends between the predicted and measured displacements can be viewed as consistent, even though the magnitudes differ significantly.

Note that the calculations were carried out by using material properties which do not correspond to the actual materials used in the experience due to lack of available data. But it is well known that the accuracy of the temperature-dependent material properties can play an important role in the accuracy of predicted stresses and distortions [15]. Furthermore, the presence of Inconel sheet may affect significantly the properties of the fusion zone. A comparison between Vickers 
macrohardness measurements in the fusion zone shows a decrease of $270 \mathrm{HV} 10$ due to the presence of Inconel 625 (around $420 \mathrm{HV} 10$ in the fusion zone without Inconel 625 versus 150 HV10 with Inconel 625) (Figure 10). The overestimation of the calculated displacements could be attributed to material properties corresponding to a stiffer behavior than those of the actual materials. However, others assumptions are also believed to contribute to discrepancies between experience and calculations. A careful examination of the clamping conditions and measurement data have to be carried out. Measurements of the thermal cycles in the vicinity of the weld pool could also be useful to validate the calculated temperatures and give insight on the weld pool size in particular in the longitudinal direction.

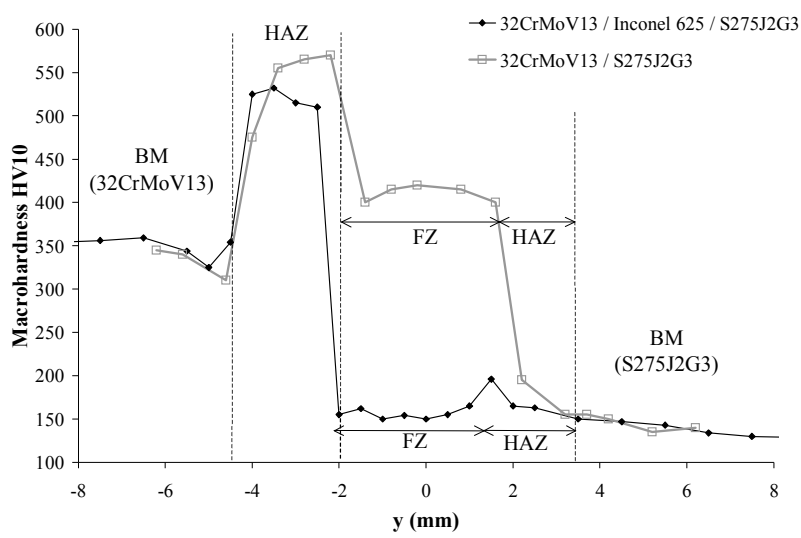

Figure 10: Comparison of the measured macrohardness. Influence of the presence of Inconel 625.

\section{CONCLUSION}

This paper featured preliminary findings in finite element studies of the opening of a electron-beam welded joint. The goal was to study the feasibility of a finite element model to predict the change in gap width during welding. Twodimensional simulations were performed and have shown that the technique using activation / deactivation of elements classically used to model a welding process in presence of material deposit could be used successfully for the opening of the joint plane. The plane stress assumption has lead to smaller displacements than those obtained with the generalized plane strain assumption and seems more adequate considering the preliminary experimental results. It was found that metallurgy has little influence on the displacements but affects the local stresses. To go further in the comparison between experience and calculations, the temperaturedependent material properties are required.

\section{ACKNOWLEDGEMENT}

This research was supported by a grant from the DCN Indret Propulsion. The authors gratefully acknowledge Vincent ROBIN from ESI for helpful discussions, Lionel RENAUDIN, Rémy BERTET and Jean-Claude PARPILLON from DCN Propulsion.

\section{REFERENCES}

[1] D.K. MILLER. Pay attention to tack and temporary welds. Welding Innovation, vol. XX, $\mathrm{n}^{\circ} 1,2003$.

[2] J. MACKERLE. Finite element analysis and simulation of welding - an addendum: a bibliography (1996-2001), Modelling Simul. Mater. Sci. Eng. 10, 295-318, 2002.

[3] J.M. BERGHEAU. Modélisation numérique des procédés de soudage, Techniques de l'Ingénieur, Traité Energétique, BM 7 758, 1-15, 2004.

[4] Y. DAIN, P.D. KAPADIA \& J.M. DOWDEN. The distortion gap width and stresses in laser welding of thin elastic plates. J. Phys. D.: Appl. Phys., 32, 168-175, 1999.

[5] L.E. LINDGREN \& R. HEDBLOM. Modelling of addition of filler material in large deformation analysis of multipass welding. Commun Numer Methods Eng, 17, 647-57, 2001.

[6] P.S. WEI \& CHIH-WEI WEN, Missed Joint Induced by Thermoelectric Magnetic Field in Electron-Beam Welding Dissimilar Metals-Experiment and Scale Analysis, Metallurgical And Materials Transactions B, 33b, 765, October 2002.

[7] D. Couedel, P. Rogeon, P. Lemasson, M. Carin, J.C. Parpillon, R. BERTHET. 2D-heat transfer modelling within limited regions using moving sources : application to electron beam welding. International Journal of Heat and Mass Transfer, 46, 4553-4559, 2003

[8] J. Belotteau. Prise en compte de la plasticité de transformation de l'acier HE360D dans la simulation du soudage. Rapport de stage de DESS GMP de l'Université de Bretagne-Sud, mars - août 2004.

[9] M. COSTANTINI: Simulation numérique du soudage par faisceau d'électrons. Contribution au développement d'un modèle prédictif de l'apport d'énergie, PhD Thesis, Université Paris 6, 1996.

[10] D. CARRon, P. ROGEON \& P. BOCQUET. Modelisation of metallurgical phase transformations in heat affected zone by using dilatometric experiments achieved in a EBW austenitizing conditions. Mathematical modelling of weld phenomena 6 Eds H. Cerjak, H.K.O.H. Bhadeshia, Institute of materials, 391409, 2001

[11] J.B. Leblond \& J.-C. DevauX. A new kinetic model for anisothermal transformation metallurgical transformations in steel including effect of austenite grain size, Acta Metallurgica. 32,1, 137-146, 1984.

[12] D.P. KoISTINEN \& R.E. MARBURGER. A general equation prescribing extend of austenite-martensite transformation in pure $\mathrm{Fe}-\mathrm{C}$ alloys and plain carbon steels. Acta Metallurgica, 7, 59-60, 1959.

[13] SYSWELD'02, Users's guide SYSTUS Int , ESI Group, Paris, 2002.

[14] ABAQUS standard software, Hibbit, Karlsson \& Sorensen, Inc.

[15] J. Song, J. Peters, A. Noor \& P. Michaleris. Sensitivty analysis of the thermomechanical response of welded joints. International Journal of Solids and Structures, 40, 4167-4180, 2003 